\title{
17
}

\section{Case Study: A Circular Business Model for Orkla and BIR?}

Since we depend on plastic packaging, we also have a part to play in the plastic problem. Can we reduce our plastic footprint by making our customers refill their plastic containers with our products instead of throwing them in the bin after a single use? Or is it a better option for our customers to return their containers so we can reuse them? And who could we collaborate with in order to get hold of discarded containers? If we use more recycled plastic, will this help in reducing the chance of whales full of plastic waste stranding on the shores while suffocating from plastic?

Bård Bringsrud Svensen, the Sustainability Innovation Manager at Orkla Home \& Personal Care, bombarded us with questions. And we bombarded him back. We were walking through the streets of Bergen vigorously discussing questions such as will customers be willing to deliver their plastic containers if they are given a discount on their next purchase? What kinds of technologies are necessary to make this happen in practice? Before Bård had left town for his flight back to Oslo, we had even discussed drone-delivered refill of cleaning products and many other 
futuristic distribution solutions to Orkla's problem: How to design a circular business model for an industry giant.

As fate would have it, around the same time as our walk with Svensen, we received a phone call from Steinar Nævdal-the CEO of the waste management company BIR. It is owned by the municipalities in the Bergen region in Norway, and it had already positioned itself as an innovative and digitally oriented player in the waste management industry, for instance, with its early adoption of an underground waste system beneath the city streets of Bergen, as well as high-tech scanning systems for waste. Nævdal had long noticed the emergence of circular thinking in business, and he thought that his company, with its dual competence in waste management and digital systems, should be in a pole position to facilitate the circular transition.

The co-occurrence of these two conversations with Svensen and Nævdal made us realize that this might be, as Humphrey Bogart said in Casablanca, "the beginning of a beautiful friendship". That is, there might be potential for an unusual alliance between the consumer products giant Orkla, the waste management company BIR and two researchers on sustainable business model innovation from the world of academia. This sparked a collaborative research project in which we build on the RESTART framework and the Business Model RESTARTer process model outlined above for developing hypotheses and experiments together with the two companies. In this case study, we shed light on this collaborative effort and emphasize how we extend and apply the frameworks from this book in practice, in a manner that can have both business-related and scientific outcomes.

\subsection{Orkla and Its Ecosystem}

Svensen, Orkla's sustainability innovation manager, is an engineer who has worked with innovation and product design his whole career. When he contacted us, he had just been assigned the responsibility for sustainability innovation in one of the largest divisions of Orkla-Orkla Home \& Personal Care. On its webpage (www.orkla.no), Orkla describes itself as follows: 
Orkla is a leading supplier of branded consumer goods to the grocery, outof home, specialised retail, pharmacy and bakery sectors. The Nordic and Baltic regions and selected countries in Central Europe are Orkla's main markets. The Orkla Group also holds strong positions in selected product categories in India. Orkla's Branded Consumer Goods business comprises the Orkla Foods, Orkla Confectionery \& Snacks, Orkla Care and Orkla Food Ingredients business areas. Orkla also has operations organised under the Orkla Investments business area, consisting of its investment in and Jotun (42.5\% interest), in addition to Hydro Power and financial assets. Orkla ASA is listed on the Oslo Stock Exchange and its head office is in Oslo, Norway. As of 31 December 2016, Orkla had 18,154 employees. The Group's turnover in 2016 totalled NOK 37.8 billion.

Orkla Home \& Personal Care is a part of Orkla Care, one of the biggest business units in Orkla. Orkla Home \& Care holds a leading position within home detergents and personal care products and competes with international corporations such as Unilever, Procter \& Gamble and Colgate-Palmolive. Unilever is perhaps the corporation in this industry that has been most successful in branding itself as sustainable, but in January 2018, Orkla's efforts to become more sustainable were also noticed. At the World Economic Forum annual event, Orkla was unveiled as one of the 100 companies included in the Corporate Knights Global 100 list of the world's most sustainable companies. However, neither Unilever nor Orkla have solved all the problems related to their substantial shadowy sides. One of the most important negative externalities in these industries is related to the use of plastic in product design and packaging, which is turning into a big headache for companies and consumers alike.

In Norway, one incident in particular fueled the public conversation about the environmental consequences of plastic usage. It happened early in 2017, when a whale was found stranded off the coast of Norway-its stomach full of 30 different types of plastic bags. According to a recent report from the World Economic Forum, at least 8 million tons of plastic already ends up in the ocean annually. It is the equivalent of a full truck of waste every minute. Many of the plastic items in the oceans are branded with famous brand names, and according to Terje Lislevand, a zoologist who examined the stranded whale in Norway, many of the labels were in 
Danish and English print. He added that the whale's intestines were probably blocked up by plastic, which would cause severe pain. This incident and the attention it received in Norwegian media put pressure on all companies that are seen as part of the plastic problem. Also, from a consumer point of view, this incident also seemed to make everyone more aware how consumption translates into concrete environmental problems that we collectively need to address.

When we met Svensen, he said that Orkla had been aware of the negative effects of the use of plastic for a long time and that they had been working on finding solutions to reduce these effects and related externalities in Orkla's business model for a long time. Svensen still had many questions regarding the way forward for Orkla Home \& Personal Care's business model. Sustainability was a large part of the problem, but at the same time, Svensen explained that factors such as increased competition from international brands and ongoing and expected changes in the retail industry because of the fourth industrial revolution were also central to their concerns. To make matters worse, the younger generations of consumers are generally less brand loyal and more willing to switch than their parents and grandparents. This implies that Orkla constantly needs to reposition itself to stay competitive. "We're not just becoming more circular, more sustainable", said Svensen. "This is also a matter of maintaining our profitability-now and in the future".

\subsection{BIR: From Waste Manager to Circular Business Partner?}

When we received the phone call from Nævdal-CEO of the BIR Group (BIR) - it was because he, his management team and the board had decided that BIR should take on a leading role in the transition from a linear to a circular economy. As a municipal entity, BIR is responsible for collecting, transporting and handling household waste, as well as industrial and hazardous waste in the regional municipalities. However, it also offers waste solutions for business. The BIR Group is Norway's second largest company in this industry with 417 employees, and in 2016, it had a turnover of NOK 736.7 million. 
The first well-known innovation project in BIR was its underground vacuum system for waste collection in Bergen, which has since been imitated by waste management companies elsewhere in the world. It is a closed, pipe-based system for collecting waste. It works almost like a giant vacuum cleaner that sucks waste from the waste collection points to central containers. Moreover, BIR has invested quite heavily in a digital waste identification system called BOSS ID (in English, WASTE ID). This system gives each user her own identity, and the customer's access to the waste system is controlled by a Radio Frequency Identification (RFID) key. In this way, BIR gets access to data about the customers, the customers pay directly for usage and BIR collects and manages valuable information about the flow of waste in its value chain. Thus, the potential for building further services based on this data can be considerable in the longer term, while in the shorter term, it allows for the optimization of BIR's operations.

We brought ORKLA and BIR together so that they could attempt to rethink their operations jointly and to see whether there might be benefits from seeing their business models in tandem. After all, massive amounts of Orkla plastic ends up in BIR's containers every year. Svensen had told us that Orkla had already come a long way in rethinking their operations, but that its managers were looking for partners who could offer solutions that the company could not provide on its own. Given BIR's innovative approach toward circular thinking, we thought that the two companies could innovate together. At the Norwegian Waste Management Conference in fall of 2017, we therefore jointly launched a research project on circular business models with particular emphasis on plastic packaging.

\subsection{Recognize-Rethink-Reinvent- Reorganize}

Together, we embarked on a problem formulation process about the future of circular business models, with Orkla as the main case. As it happened, Orkla had recently launched a new brand and product 
portfolio series that would in part cannibalize on its well-known soap and detergent products. The series is called KLAR — a word that in Norwegian can mean "clear", "transparent", as well as "ready". The product line is vegan, its formulations are sustainable, of course free from microplastics, and packaged in 100 percent recycled plastic. The KLAR concept was chosen as an initial case for our research project, which implied that the manager responsible for the development of the brand and the product portfolio, Anne Marheim Støren, became an important part of our research project.

The case of sustainable cleaning products is particularly interesting for many reasons. First, it is a product category most, if not all, households rely on. Importantly, however, there had scarcely been any sustainable products in this category and to the extent that there had been, customers generally did not seem to trust their quality. Since these products constitute a low involvement and habit-based product category, we were particularly intrigued by the challenge of working with a company like Orkla to investigate how consumer behavior and habits could be changed to embrace more sustainable solutions. This made it necessary to understand several aspects of consumer behavior related to such products: the barriers and drivers of adoption, the beliefs about effectiveness and the preferences for or against such products and the decisive characteristics and messages that could drive consumers to change from less sustainable to more sustainable products.

We based our work process on the three phases in the Business Model Restarter, and at the time of writing, we are still somewhere in between rethinking and reinventing. In the early phases of the process, we ran workshops with the two companies and crowdsourced the viewpoints and ideas of a group of innovators at the Innovation Festival 2017 in Andalsnes, Norway. There, we hosted an interactive workshop wherein participants generated and discussed ideas for the future distribution of home care products. At a workshop with BIR and Orkla at the end of 2017, however, a shortlist of sub-projects to be pursued further was developed. We facilitated this work in close collaboration with business developer Tore Totland and Anders Waage Nilsen, two freethinking individuals whose help BIR had also enlisted when embarking on this jour- 
ney. Together, we designed the four sub-projects, and we began thinking more concretely about how empirical studies could be derived from each of the projects.

The different groups of project members from BIR, Orkla and the academic institutions generated four problems to be solved along a circular chain. In order to solve the problem of plastic circularity in practice, at least four challenges must be overcome: First, in order for circularity to function for plastic products, the products must be designed and manufactured in a manner that makes them recyclable (cf. Bocken et al. 2014). A project group was formed to address this challenge, which at least initially is more a technical and practical process than a research project, although there might be opportunities for scientific studies at a later stage. Second, once products are distributed to stores, knowledge of consumer behavior in the store and at home is essential. Here, a project group was formed to design lab and field experiments on consumer behavior related to the choice of an explicitly "green" product series such as KLAR — a strand of literature already rich on interesting findings. Moreover, there was a clear intention to dig deeper into the life of the product after consumers brought it home-a topic that could be investigated by groups of master students, for instance.

Third, in order to connect the business models of Orkla and BIR, the third sub-project related to the systems, solutions and incentives for getting consumers to return the packaging after the product had been discarded. A project group with both practitioners and academics was tasked with developing ideas for such systems and to envision testable solutions in the field. Fourth, in the more practical end, a group was formed for investigating the question of how collected plastics could be "led back to" Orkla, so that yesterday's KLAR containers could become the Orkla packaging of tomorrow.

By forming these four groups and commencing the work in each four of them, the innovation process starts leaning from a rethink phase to a reinvent phase. That is, as ideas are generated and in due course tested scientifically or through various forms of $\mathrm{A} / \mathrm{B}$ tests or pilots by the companies, opportunities for actually changing the business models of the companies emerge. Thus far, we have mostly been explicit about how 
Orkla's business model might change. But what about BIR? What are the characteristics of a successful outcome for such a company in a process like this? Will BIR need to change its business model in a way that involves differentiated payment from companies that either would like to purchase generic recycled materials versus, for instance, recycled materials that are in fact based on its own prior goods being returned and recycled? Or should BIR be paid not for waste management but for waste avoidance, as the company Norsk Gjenvinning also asked itself, as detailed in the case in Part II of the book?

It is too soon to tell where the project with Orkla and BIR will end up, and what will be the outcomes for the partners involved. The preceding description, however, attempts to account for a messy innovation process in which there are explicit desires from all partners to run scientific studies, in general, and experiments, in particular, in order to reveal some of the factors that can help companies achieve more circular business models. The remainder of the story will have to be told another day.

\subsection{Restarting Together: More Cake for All?}

We have argued that alliances such as the one described above can increase the value created for all players and may even have beneficial outcomes for society and the environment. By no means, however, do we believe that succeeding with such alliances is an easy task. Fortune favors the bold, some say, and it is at least our impression thus far that by embarking on this unusual and ambitious collaboration with players from different industries as well as academics with other objectives, time horizons and mindsets, BIR and Orkla have opened doors to new ways of thinking about how they create, deliver and capture value.

\section{Reference}

Bocken, N. M. P., Short, S. W., Rana, P., \& Evans, S. (2014). A literature and practice review to develop sustainable business model archetypes. Journal of Cleaner Production, 65, 42-56. 
Open Access This chapter is licensed under the terms of the Creative Commons Attribution-NonCommercial-NoDerivatives 4.0 International License (http:// creativecommons.org/licenses/by-nc-nd/4.0/), which permits any noncommercial use, sharing, distribution and reproduction in any medium or format, as long as you give appropriate credit to the original author(s) and the source, provide a link to the Creative Commons license and indicate if you modified the licensed material. You do not have permission under this license to share adapted material derived from this book or parts of it.

The images or other third party material in this chapter are included in the chapter's Creative Commons license, unless indicated otherwise in a credit line to the material. If material is not included in the chapter's Creative Commons license and your intended use is not permitted by statutory regulation or exceeds the permitted use, you will need to obtain permission directly from the copyright holder.

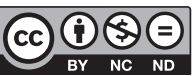

